\title{
Preparação e caracterização de extratos glicólicos enriquecidos em taninos a partir das cascas de Stryphnodendron adstringens (Mart.) Coville (Barbatimão)
}

\author{
Ardisson, L. ${ }^{1}$; Godoy, J. S. ${ }^{1}$, Ferreira, L. A. M. ${ }^{2}$, Stehmann, J. R. ${ }^{3}$;Brandão, M. G. L.. ${ }^{*}$ \\ ${ }^{1}$ Laboratório de Farmacognosia ; ${ }^{2}$ Laboratório deTecnologia Farmacêutica, Faculdade de Farmácia; \\ ${ }^{3}$ Departamento de Botânica, Instituto de Ciência Biológicas, Universidade Federal de Minas Gerais, \\ Belo Horizonte, MG.
}

\begin{abstract}
RESUMO: Neste estudo, foram preparados e caracterizados extratos glicólicos de cascas de Stryphnodendron adstringens (barbatimão), visando a obtenção de extratos enriquecidos em taninos. Os extratos foram preparados, em triplicata, por meio de maceração estática da droga vegetal pulverizada, seguida de percolação, com diferentes misturas de $90 \%$ (PGL90), 80\% (PGL80) e 70\% (PGL70) de propilenoglicol em água. Os extratos foram recolhidos de forma fracionada. Cada fração obtida foi submetida a análises de $\mathrm{pH}$, densidade, determinação de resíduo seco, e dos teores de taninos e de polifenóis. Os resultados dessas análises demonstraram que o solvente PGL70 extraiu maior quantidade de constituintes químicos da droga vegetal, a partir das primeiras frações. No entanto, as análises revelaram que o solvente PGL80 foi mais seletivo ao extrair, especificamente, os taninos da planta. Os resultados indicaram que a incorporação de $20 \%$ de água ao propilenoglicol deve conduzir a extratos mais enriquecidos em taninos, a partir das cascas de barbatimão.
\end{abstract}

Unitermos: barbatimão; Stryphnodendron adstringens; taninos; propilenoglicol; extrato glicólico.

ABSTRACT: Preparation and characterization of propylene glicol extracts obtained from dried stem barks of Stryphnodendron adstringens (Mart.) Coville (barbatimão). Extracts from dried stem barks of Stryphnodendron adstringens (barbatimão) were prepared with $90 \%$, $80 \%$ and $70 \%$ of propylene glycol and water (PGL90, PGL80 and PGL70, respectively). The extract was prepared by percolation and collected as fractions of $100 \mathrm{~mL}$. The $\mathrm{pH}$, density, dry residue and tannin and polyphenolic contents were determined for each fraction. The results showed that the extraction of chemical compounds was more efficient with PGL70, but PGL80 was more selective for extraction of tannins, the active compounds.

Key words: barbatimão; Stryphnodendron adstringens; tannins; propylene glicol extracts.

\section{INTRODUÇÃO}

Espécies do gênero Stryphnodendron, conhecidas como barbatimão, são amplamente utilizadas no Brasil como cicatrizante e a eficácia de preparações com a planta já foi confirmada por vários estudos. JORGE-NETO et al. (1996), por exemplo, descreveram uma melhor eficácia da associação de tinturas de barbatimão e calêndula em relação à tintura de calêndula isolada, no 
tratamento de úlcera varicosa. CARVALHO et al. (1991) comprovaram a ação de preparações aquosas das cascas da planta, na cicatrização cutânea de feridas. FAVORETO et al. (1985) demonstraram a efetividade dessas preparações no tratamento de úlceras de contenção em ratos. O alto teor de taninos nas cascas (MELLO et al., 1999) é, provavelmente, o que explica a atividade cicatrizante. No processo de cicatrização, os taninos precipitam as proteínas dos tecidos lesados, formando um revestimento protetor que favorece a sua regeneração (HEIJMEN et al., 1997; PANIZZA et al., 1998). Seria interessante, portanto, o desenvolvimento de produtos com a planta, os quais possam ser utilizados para o tratamento de feridas.

O propilenoglicol é um solvente viscoso, utilizado em uma grande variedade de formulações farmacêuticas de uso tópico, devido à sua propriedade emoliente (DIEMUNSCH e MARTHIS, 1980; HANDBOOK, 1994). O propilenoglicol é, também, largamente empregado na preparação de extratos vegetais, conhecidos como extratos glicólicos. Apesar da ampla utilização e comercialização desses extratos, pouco se conhece sobre os melhores métodos para obtenção dos mesmos, como também, a adequada proporção de água necessária para extrair os constituintes químicos ativos das diferentes plantas.

Neste estudo, foram caracterizados os extratos glicólicos de barbatimão, preparados com diferentes concentrações de propilenoglicol e água. O objetivo final é o desenvolvimento de um método simples de obtenção desses extratos, para que possam ser utilizados na preparação de produtos de uso tópico, no tratamento de feridas.

\section{MATERIAIS E MÉTODOS}

\section{Material botânico}

Amostras de barbatimão foram coletadas na região de Curvelo (MG), em junho de 1999 e identificadas como sendo de Stryphnodendron adstringens (Mart.) Coville pelo Prof. João Renato Stehmann (exsicata número BHCB 4720). As cascas foram secas à sombra, em temperatura ambiente e local ventilado, e pulverizadas em moinho de facas.

\section{Determinação da granulometria dos pós}

Utilizou-se uma bateria de tamises com as seguintes aberturas nominais de malha $(\mu \mathrm{m})$ : $2000,1700,1400,1180,1000,840$ e 180. Cerca de $100 \mathrm{~g}$ do pó da droga vegetal foram colocados sobre o primeiro tamis da bateria. Tampou-se e agitou-se manualmente, com movimentos horizontais rotativos e movimentos verticais, por 20 minutos, no mínimo. Utilizou-se um pincel para retirar o pó fino aderido às paredes do tamis, passando-se ao tamis seguinte. Pesou-se, cuidadosamente, com precisão de $100 \mathrm{mg}$, o material remanescente em cada tamis e os resultados foram expressos como porcentagem da quantidade total (WHO, 1992).

\section{Caracterização farmacognóstica da droga vegetal}

- Teor de umidade: foi realizado pelo método gravimétrico, constante na Farmacopéia Brasileira (2000), em triplicata;

- Teor de cinzas totais: foi realizado pelo método constante na Farmacopéia Brasileira (2000), em triplicata;

- Determinação quantitativa de taninos e polifenóis: foi utilizado o método preconizado pela Farmacopéia Brasileira (2000), para a determinação de taninos da hamamélis. 


\section{Preparação dos extratos em propilenoglicol}

Os extratos foram preparados por meio de maceração estática da droga vegetal pulverizada, seguida de percolação, com diferentes misturas de 90\% (PGL90), 80\% (PGL80) e 70\% (PGL70) de propilenoglicol (Galena Ltda.) em água. Antes de serem introduzidos nos percoladores, os pós foram misturados a $10 \%$ de sílica para coluna cromatográfica (Carlo Erba, $n^{\circ} 453337$ ), com o objetivo de se evitar a formação de canais preferenciais e permitir a passagem do solvente extrator através da droga, de forma homogênea. Cem gramas dessa mistura foram umedecidos com q.s.p. de solvente extrator e deixados macerar em um funil de separação (preparado como um percolador), por um período de 48 horas. Após este tempo, iniciou-se o processo de percolação, sendo cada extrato recolhido de forma fracionada (frações de $100 \mathrm{~mL}$ ). Esse procedimento foi repetido até a obtenção de 5 frações para cada percolador (F1 a F5), ou seja, $500 \mathrm{~mL}$. Cada extrato foi preparado em triplicata. A Figura 1 ilustra o método de obtenção das frações dos extratos, a partir das cascas de S. adstringens.

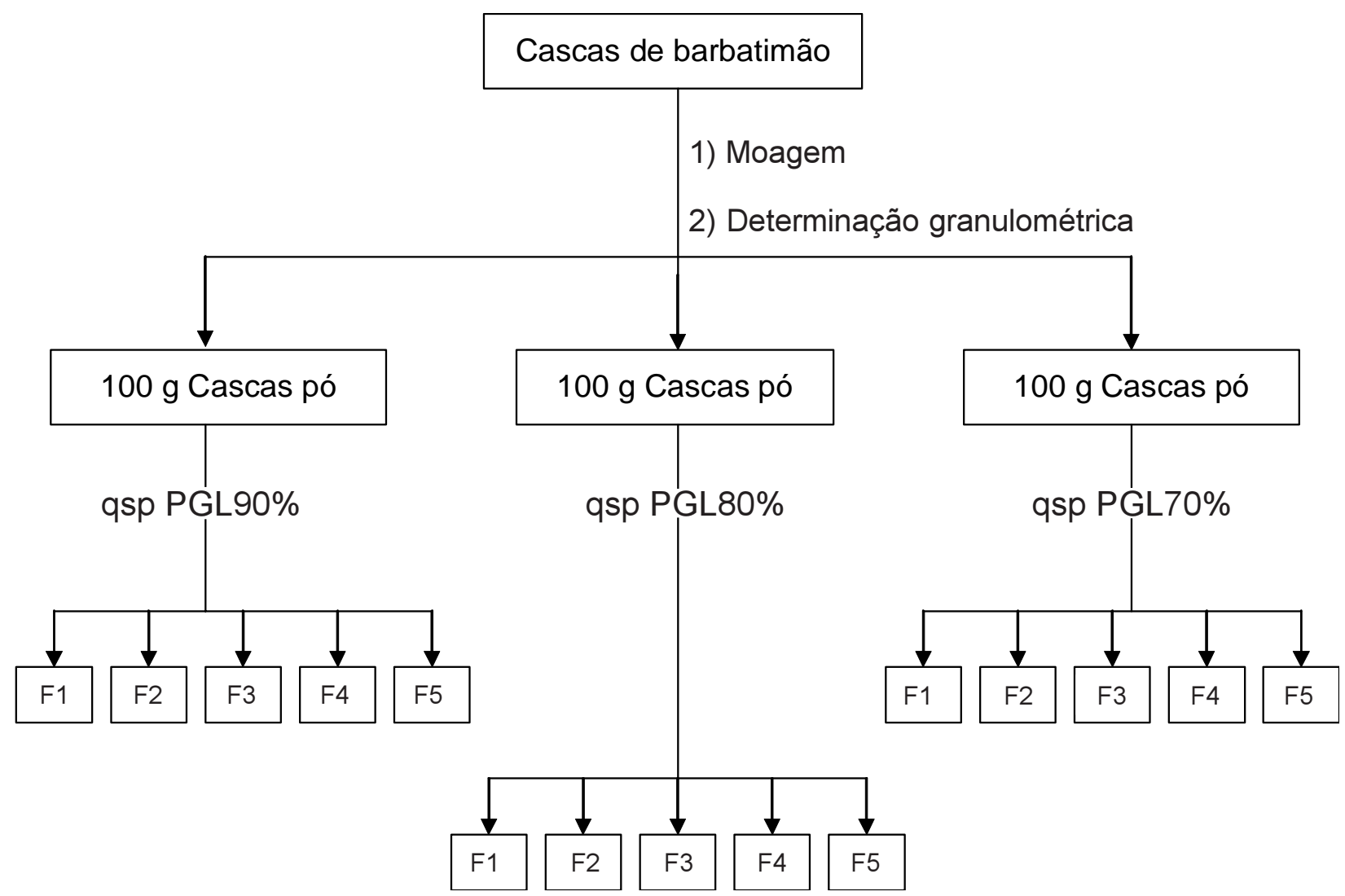

Figura 1. Método de obtenção (percolação estática) das frações (F1 a F5) dos extratos das cascas de Stryphnodendron adstringens. Cada extrato foi preparado em triplicata.

\section{Análise físico-química e química dos extratos}

Cada uma das frações (F1 a F5) foram submetidas à:

- Determinação do pH. Foram determinados em potenciômetro. Os valores de pH dos solventes extratores puros foram 6,15 para a mistura PGL90; 6,47 para PGL80 e 6,32 para PGL70;

- Determinação da porcentagem do resíduo seco. Um mililitro de cada uma das frações foi exatamente medido e transferido para cápsulas de porcelana, previamente taradas. 
As cápsulas foram colocadas em banho-maria até a secura e levadas, posteriormente, à estufa sob a temperatura de $110^{\circ} \mathrm{C}$, até peso constante. As cápsulas foram pesadas e a porcentagem de resíduo seco, calculada;

- Determinação da densidade. A densidade de cada uma das frações foi determinada pelo método do picnômetro (sob temperatura de $25^{\circ} \mathrm{C}$ ). Os valores obtidos para as misturas de solventes foram 1,04 para PGL90; 1,08 para PGL80 e 1,05 para PGL70;

- Determinação quantitativa dos taninos e polifenóis presentes nos extratos glicólicos. Foi realizada a mesma técnica descrita para a droga vegetal, com alíquotas dos extratos glicólicos que permitissem a leitura espectrofotométrica (absorvância) dentro de uma faixa de linearidade (Ardisson, 2000).

\section{RESULTADOS E DISCUSSÃO}

Após tamização, o pó da planta apresentou $53 \%$ de partículas de tamanho inferior a 840 e superior a $180 \mathrm{~mm}\left(d_{50}=330 \mathrm{~mm}\right)$. O teor de umidade ficou na faixa de 10,24\% $( \pm 0,16)$, de acordo com o limite máximo permitido pela F.Bras. $4^{a} E d$. (2000) que é de, no máximo, 14\%. O teor de cinzas foi de 1,64 $( \pm 0,09)$, dentro do valor especificado na monografia para o $S$. adstringens na F.Bras. $2^{\mathrm{a}} \mathrm{Ed}$. (1959), que é de, no máximo, $5 \%$. Os teores de polifenóis totais e taninos na droga vegetal foram de $30,8 \%( \pm 0,38)$ e $29,9 \%( \pm 0,52)$, respectivamente, próximo do valor encontrado por PANIZZA et al. (1988) para as cascas do $S$. adstringens que foi de 25 a $30 \%$ de taninos. Todos estes resultados indicaram que as cascas coletadas encontram-se dentro das especificações descritas na literatura para esta droga vegetal.

A Figura 2 apresenta as médias dos valores de $\mathrm{pH}$ obtidos para cada fração dos diferentes extratos. Os valores de $\mathrm{pH}$ decresceram, consideravelmente, em relação aos solventes puros, cujos valores de pH eram em torno de 6,0. As quatro primeiras frações (F1 a F4), obtidas com o solvente PGL70, apresentaram-se mais ácidas ( $\mathrm{pH}$ variando de 4,87 a 5,35) em comparação com os valores obtidos para essas mesmas frações com os solventes PGL80 (pH variando de 4,94 a 5,49 ) e PGL90 ( $\mathrm{pH}$ variando de 4,94 a 5,53). Esses resultados parecem indicar que, a princípio, os solventes com maiores concentrações de água conduzem a extratos mais enriquecidos em polifenóis e taninos, que têm características ácidas.

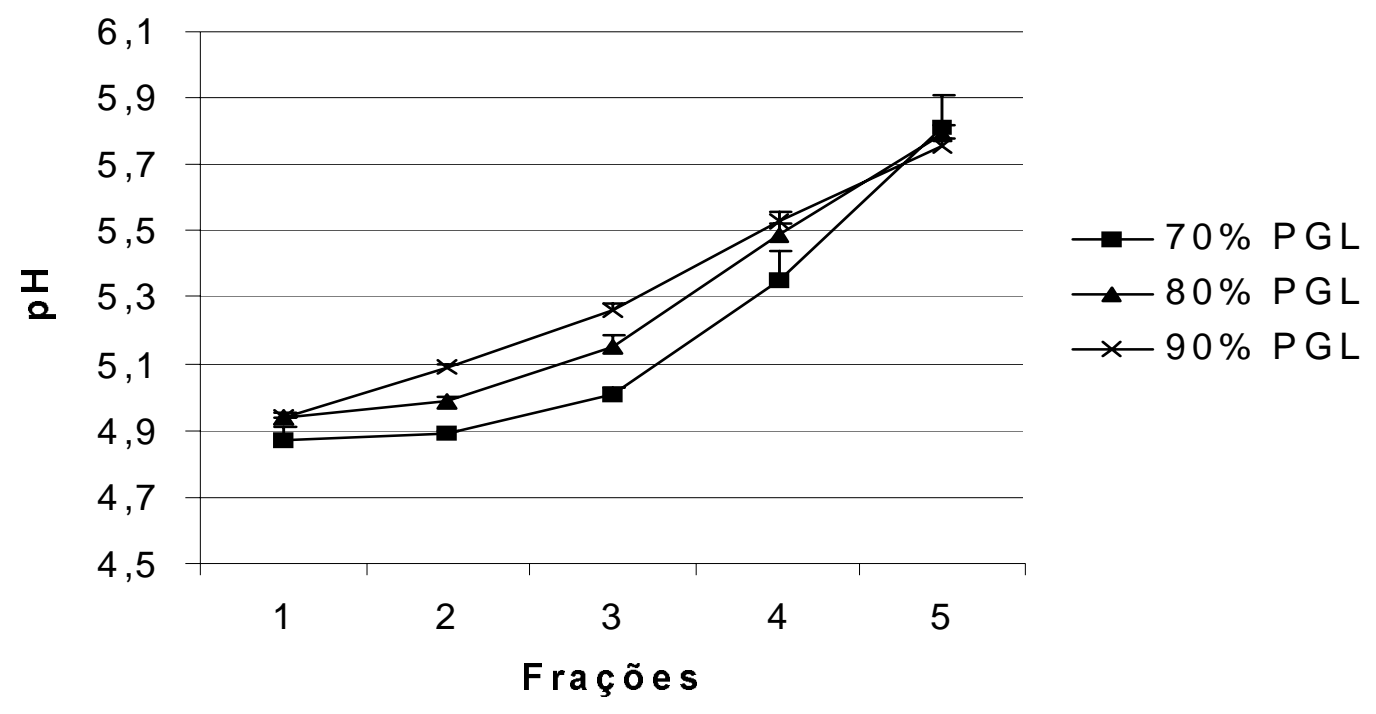

Figura 2. Comparação entre as médias dos valores de $\mathrm{pH}$ obtidos para cada fração dos diferentes extratos glicólicos de Stryphnodendron adstringens. 
A Figura 3 apresenta as porcentagens de resíduos secos de cada fração dos diferentes extratos. As frações F1 a F3 do extrato PGL70 apresentaram teores de resíduo significativamente maiores $(25,9 \%, 14,3 \%$ e $8,9 \%$ respectivamente) do que aqueles obtidos para $\mathrm{F} 1$ a F3 dos demais extratos $(21,1 \%, 10 \%$ e $2,6 \%$ para PGL80 e 20,7\%, 11,7 e 2,3\% para PGL90, respectivamente). Esses resultados indicam que o solvente constituído por $70 \%$ de propilenoglicol é capaz de extrair maior quantidade de substâncias da planta, desde as primeiras frações. Observa-se, ainda, que em todos os sistemas, o esgotamento da droga aconteceu após a passagem de $300 \mathrm{~mL}$ de solvente.

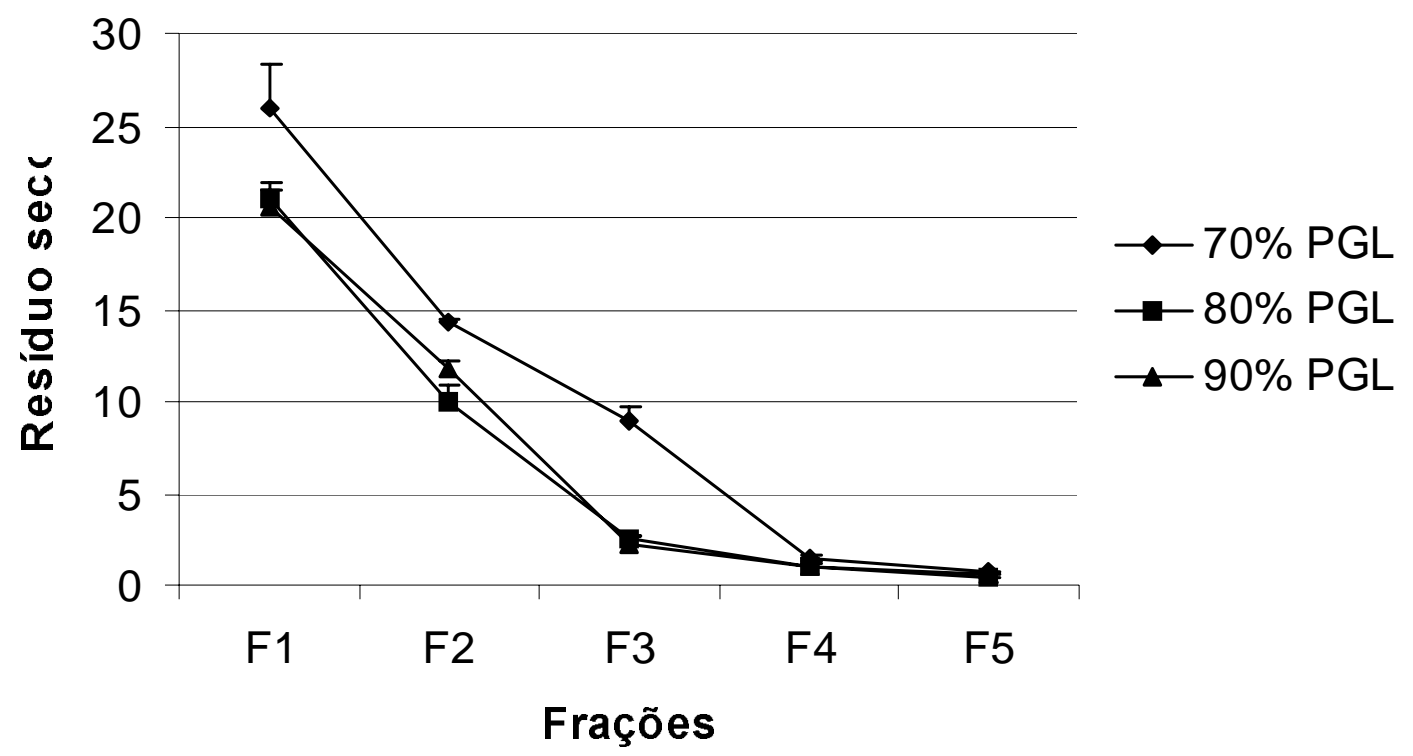

Figura 3. Comparação entre as médias das porcentagens dos valores de resíduo seco obtidos para cada fração dos diferentes extratos glicólicos de Stryphnodendron adstringens.

Com relação à densidade, houve um aumento significativo dos valores obtidos para os extratos em relação aos solventes puros. No extrato PGL90, os valores de densidade de F1 a F5 variaram de $1,45( \pm 0,02)$ a 1,37 $( \pm 0,00)$. Nos extratos PGL80 e PGL70 os valores variaram de $1,46( \pm 0,02)$ a $1,38( \pm 0,00)$. A pouca variação desses valores de densidade, em detrimento aos resíduos secos obtidos anteriormente, pode ser uma conseqüência das diferentes concentrações de água nos extratos.

A Figura 4 apresenta os teores de taninos obtidos para cada fração dos diferentes extratos. As frações F1 a F3 dos extratos PGL70 e PGL80 apresentaram teores de taninos significativamente superiores àqueles obtidos para as mesmas frações do extrato PGL90. Esses resultados confirmam que os sistemas constituídos de 70 e $80 \%$ de propilenoglicol são os mais apropriados para a extração de taninos, conduzindo a extratos mais enriquecidos nestas substâncias. Esta figura mostra, também, que a concentração de taninos diminuiu consideravelmente a partir de F3, sendo que em F4 e F5 essas substâncias encontravam-se praticamente ausentes. O mesmo comportamento foi observado para os teores de polifenóis 
totais dos extratos que variaram de $5,1( \pm 0,43)$ a $0,2( \pm 0,03)$ para F1 a F5 do extrato PGL90, de $14,5( \pm 1,74)$ a $0,49( \pm 0,09)$ para o extrato PGL80 e $15,7( \pm 0,86)$ a $0,42( \pm 0,09)$ para o extrato PGL70, respectivamente.

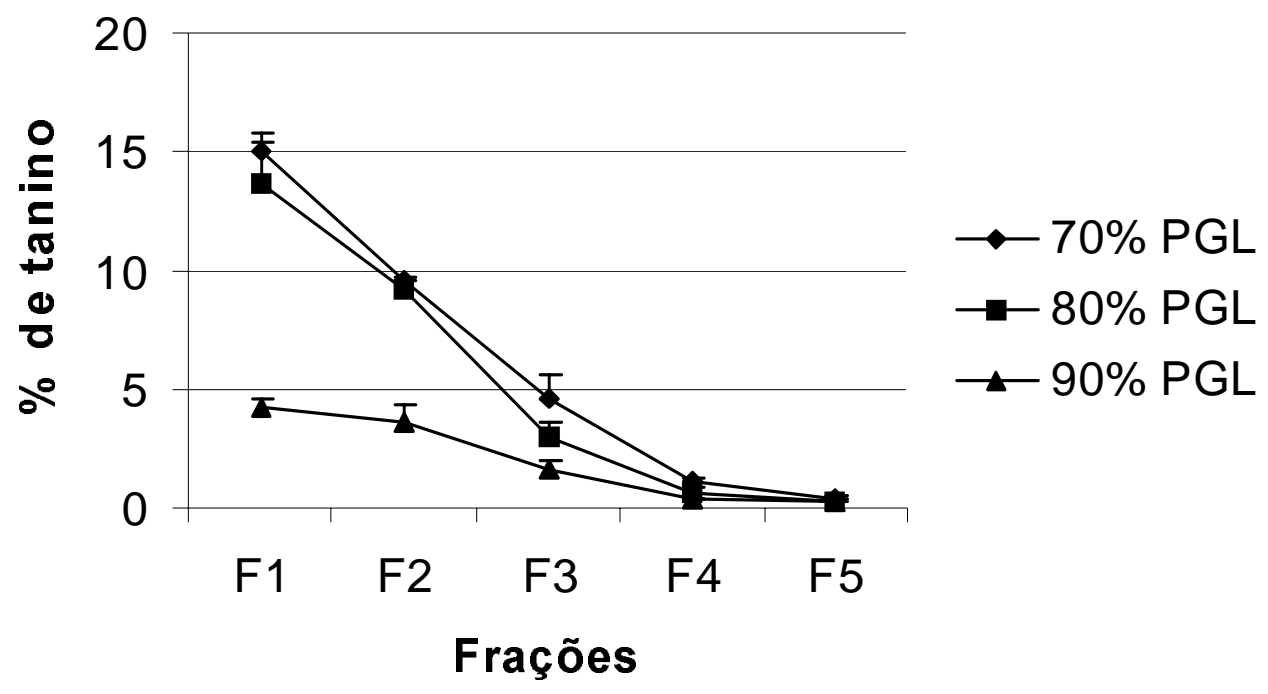

Figura 4. Comparação entre as médias das porcentagens dos teores de taninos presentes em cada fração dos diferentes extratos glicólicos de Stryphnodendron adstringens.

A seletividade de cada sistema de solventes em extrair especificamente os taninos, prováveis constituintes ativos da droga, foi determinada a partir do cálculo da razão entre os teores totais dessas substâncias e dos resíduos secos obtidos para cada extrato (índice de seletividade). Quanto mais próximo de 1,0 maior é a seletividade do solvente em extrair os taninos da droga vegetal. A Tabela 1 mostra o somatório (F1 a F5) dos resíduos secos e taninos totais obtidos para cada extrato. Observa-se que o solvente PGL70 forneceu maior porcentagem final de resíduo seco $(51,7 \%)$ em comparação com os valores obtidos para os extratos PGL80 e PGL90 (36,2\% e 36,3\%, respectivamente). O teor de taninos obtido com o solvente PGL70 $(30,8 \%)$ também foi superior aos dos demais extratos $(26,9 \%$ para PGL80 e $10,4 \%$ para PGL90). No entanto, o índice de seletividade apresentado pelo solvente PGL80 $(0,74)$ foi maior do que aquele observado para os demais extratos $(0,59$ para $P G L 70$ e 0,28 para PGL 90). Esses resultados sugerem que o solvente PGL80 é mais específico para extrair os taninos da droga vegetal. 
Tabela 1. Porcentagens totais de resíduo seco e de taninos obtidas com os diferentes extratos glicólicos de Stryphnodendron adstringens e os respectivos índices de seletividade.

\begin{tabular}{|c|c|c|c|}
\hline \multirow{2}{*}{$\begin{array}{l}\text { EXTRATO } \\
\text { GLICÓLICOS }\end{array}$} & \multicolumn{3}{|c|}{ TEORES DE EXTRATIVOS } \\
\hline & \% Resíduo Seco & $\%$ Taninos & Índice de Seletividade \\
\hline PGL90 & 36,3 & 10,4 & 0,28 \\
\hline PGL80 & 36,2 & 26,9 & 0,74 \\
\hline PGL70 & 51,7 & 30,8 & 0,59 \\
\hline
\end{tabular}

\section{CONCLUSÃO}

Os resultados dessa pesquisa revelaram que a incorporação de $20 \%$ de água ao propilenoglicol conduz a extratos mais enriquecidos em taninos, obtidos a partir das cascas de $S$. adstringens. São necessários, portanto, novos estudos que avaliem as melhores condições para obtenção de extratos de glicólicos enriquecidos em substâncias ativas a partir de outras plantas medicinais.

\section{REFERÊNCIAS BIBLIOGRÁFICAS}

ARDISSON, L. Estudo do comportamento do propilenoglicol como solvente extrator para as cascas do Stryphnodendron adstringens (Mart.) Coville (barbatimão), planta utilizada na medicina popular no tratamento de feridas. Belo Horizonte, 74p. Monografia. Faculdade de Farmácia, Universidade Federal de Minas Gerais, 2000.

CARVALHO, P. S. P. ; TAGLIAVINI, D. G.; TAGLIAVINI, R. L. Cicatrização cutânea após a aplicação tópica de creme de calêndula e de associação de confrei, própolis e mel em feridas infectadas: Um estudo clínico e histológico em ratos. Revista de Ciências Biomédicas, v.12, p.39-50, 1991.

DIEMUNSCH, A. M.; MARTHIS, C. Preparation et controle d'extraits végétaux à usage cosmétologique. Labo-Pharma-Problèmes et Techniques, v. 294, p.55-63, 1980.

FARMACOPÉIA BRASILEIRA. 2. ed. São Paulo: Indústria Gráfica Siqueira, 1959.

FARMACOPÉIA BRASILEIRA. 4. ed. São Paulo: Atheneu, 2000.

FAVORETO, L.V.; CONTRERA, M. G. D.; PETENUSCI, S. O.; SILVA-NETO, C.; LOPES, R. A; SATAKE, T. Ação cicatrizante do extrato aquoso da casca do barbatimão Stryphnodendron obovatum em úlcera por contenção em ratos. Revista da Escola de Farmácia e Odontologia de Alfenas, v.8, p.7-12, 1985.

HANDBOOK of Pharmaceutical Excipients. 2.ed. Washington: American Pharmaceutical Association, 1994. 651p.

HEIJMEN, F. H.; DU PONT, J. S.; MIDDELKOOP, E.; KREIS, R. W.; HOEKSTRA, M. J. Crosslinking of dermal sheep collagen with tannic acid. Biomaterials, v.18, n.10, p.749-754, 1997. 
JORGE-NETO, J.; FRACASSO, J. F.; CAMARGO-NEVES, M. C. L.; SANTOS, L. E.; BANUTH, V. L. Tratamento de úlcera varicosa e lesões de pele com Calendula officinalis L. elou com Stryphnodendron barbatiman (Vellozo) Martius. Revista Ciências Farmacêuticas, v.17, p.181-6, 1996.

MELLO, J. C. P.; PETEREIT, F.; NAHRSTEDT, A. A dimeric proanthocyanidin from Stryphnodendron adstringens. Phytochemistry, v. 5, p.1105-1107, 1999.

PANIZZA, S.; ROCHA, A. B.; GECCHI, R.; SOUZA-SILVA, R.; PENTEADO, R. Stryphnodendron barbatiman (Vellozo) Martius: teor em taninos na casca e sua propriedade cicatrizante. Revista de Ciências Farmacêuticas, v.10, p.101-6, 1988.

WHO HEALTH ORGANIZATION. Quality control methods for medicinal plant materials. 1992.

Recebido para publicação em: 22/04/2002 Aceito para publicação em: 31/07/2002

\section{*Autor para correspondência:}

Profa. Dra. Maria das Graças Lins Brandão Laboratório de Farmacognosia Departamento de Produtos Farmacêuticos Faculdade de Farmácia Universidade Federal de Minas Gerais. Av. Olegário Maciel, 2360 30180-112 - Belo Horizonte-MG E-mail: branlins@dedalus.lcc.ufmg.br 